
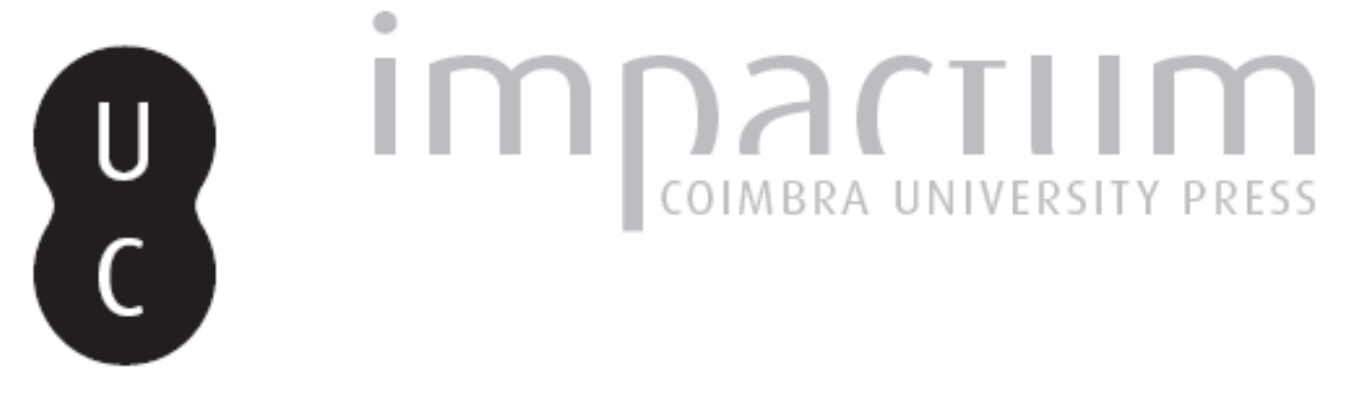

\title{
Princípios e regras: uma abordagem evolutiva
}

\author{
Autor(es): $\quad$ Baltazar, Antonio Henrique Lindemberg
}

Publicado por: Universidade Católica de Petrópolis

URL persistente:

URI:http://hdl.handle.net/10316.2/33876

DOI:

DOI:http://dx.doi.org/10.14195/2175-0947_1-2_4

Accessed : $\quad$ 26-Apr-2023 14:57:54

A navegação consulta e descarregamento dos títulos inseridos nas Bibliotecas Digitais UC Digitalis, UC Pombalina e UC Impactum, pressupõem a aceitação plena e sem reservas dos Termos e Condições de Uso destas Bibliotecas Digitais, disponíveis em https://digitalis.uc.pt/pt-pt/termos.

Conforme exposto nos referidos Termos e Condições de Uso, o descarregamento de títulos de acesso restrito requer uma licença válida de autorização devendo o utilizador aceder ao(s) documento(s) a partir de um endereço de IP da instituição detentora da supramencionada licença.

Ao utilizador é apenas permitido o descarregamento para uso pessoal, pelo que o emprego do(s) título(s) descarregado(s) para outro fim, designadamente comercial, carece de autorização do respetivo autor ou editor da obra.

Na medida em que todas as obras da UC Digitalis se encontram protegidas pelo Código do Direito de Autor e Direitos Conexos e demais legislação aplicável, toda a cópia, parcial ou total, deste documento, nos casos em que é legalmente admitida, deverá conter ou fazer-se acompanhar por este aviso.

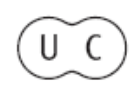



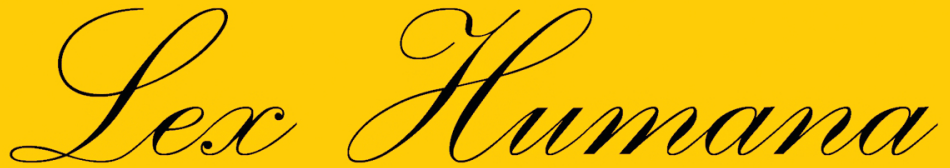

Revista do Programa de Pós-Graduação em Direito da UCP

ISSN(e) 2175-0947

Universidade Católica de Petrópolis Rua Benjamin Constant, 213 - Petrópolis - Centro CEP 25610-130

Tel: (24) 2244-4000 E-mail: lexhumana@ucp.br 


\section{PRINCÍPIOS E REgRAS: \\ UMA ABORDAGEM EVOLUTIVA}

Antonio Henrique Lindemberg Baltazar ${ }^{1}$,

Resumo: Este trabalho pretende realizar uma reflexão sobre o atual modelo constitucional principiológico. Para tanto, adotamos como metodologia a abordagem histórico-evolutiva do Estado Jusnaturalista ao moderno Estado Pós-Positivista. A evolução jurídica, desde o jusnaturalismo até o pós-positivismo nos mostra a tentativa de se lançar mão de um Estado principiológico, cujos valores são alçados como fundamento do edifício jurídico.

Palavras-chave: Jusnaturalismo. Positivismo. Pós-Positivismo.

Abstract: This paper aims at reflecting on the current constitutional model framed by a set of principles. In order to fulfill this purpose, a methodology based on a histor $\neg$ ical-evolutionary approach was taken concerning the modern State built on the con $\neg$ ception of natural law until the post-positivism. The legal developments observed from natural law to post-positivism show an attempt to rely on a State based on principles, in which values are considered the fundamentals of the legal structure.

Keywords: Jusnaturalism. Legal Positivism. Post-positivism.

\section{Do jusnaturalismo ao pós-positivismo}

O jusnaturalismo fundamenta-se na existência de um direito, imanente à natureza, universal, imutável, suprapositivo e, principalmente, absolutamente justo ${ }^{2}$. Inspirado nas teorias de Hugo Grócio (1583-1645), Thomas Hobbes (1588-1679) e Pufendorf (1632-94), a idéia fundamental da teoria naturalista é a afirmação da existência de preceitos de justiça que independem da normatização realizada pelo Estado, estando acima do direito posto pelo Estado (caráter suprapositivo do direito natural)3. Daí

1 Mestre em Direito Constitucional (Instituto Brasiliense de Direito Público - IDP-DF), Professor da Faculdade de Ciências Sociais e Aplicadas de Diamantino - UNED

2

. KELSEN, 2003, pp. 67-117.

3 Conforme aponta Norberto Bobbio, o naturalismo não pressupõe a inexistência do direito positivo, apenas postula a superioridade daquele, enquanto o positivismo pressupõe a inexistência do 
decorre o reducionismo da validez do direito aos ideais de justiça e eticidade, passando a se considerar jurídicas apenas as normas justas, isto é, aquelas que coincidam seus comandos com o que proposto pelo direito natural ${ }^{4}$.

Seus principais teóricos podem ser agregados em duas correntes ${ }^{5}$ : (i) aqueles que postulavam como fonte do direito natural a vontade de Deus, de cunho notadamente teológico e (ii) aqueles que afirmavam ser a razão a fonte do direito natural ${ }^{6}$.

Enquanto o jusnaturalismo originário tinha profundas bases teológicas, o moderno jusnaturalismo do século XVII abandona as idéias de um direito baseado na vontade de Deus e funda-se na razão como substrato legitimador dos direitos inerentes ao ser-humano. É com esta pretensão que se iniciam os movimentos revolucionários liberal-burgueses que, afirmando a necessidade de o Estado respeitar e proteger os direitos naturais, articula a queda do absolutismo monárquico. Essa doutrina jusnaturalista serviu de fundamento ao aparecimento de dois princípios fundamentais ao nascimento do estado liberal: o princípio da tolerância religiosa e o da limitação dos poderes do estado. ${ }^{7}$

Importante é apontar a relevância dos ideais naturalistas nas revoluções liberais do século XVIII, principalmente em França e na América, sendo prova inquestionável de sua importância o Preâmbulo da Declaração universal dos direitos do homem e do cidadão, o qual prescreve que:

O Povo Francês, convencido de que o esquecimento e o desprezo dos direitos naturais do Homem são as

direito natural. Neste sentido, aponta o autor que "por jusnaturalismo entendo aquela corrente que admite a distinção entre direito natural e direito positivo e sustenta a supremacia do primeiro sobre o segundo. Por positivismo jurídico entendo aquela corrente que não admite distinção entre direito natural e direito positivo e afirma que não existe outro direito que o direito positivo". BOBBIO, 1965, p. 68.

4 DÍAS, 1998, p. 40.

$5 \quad$ Na verdade, para fins deste trabalho, optamos por sintetizar os modelos do jusnaturalismo. Entretanto não desconhecemos a importância do modelo da antiguidade clássica representado na filosofia grega pela dicotomia physikón/nomikón dikaion e do direito romano fundamentado no jusnaturale/ jusgentium/juscivile, nem da escola racional do direito que possui como principais teóricos Kant e Rousseau.

6

Hugo Grócio (1583-1645) expõe em sua obra De iure belli ac pacis, de 1625 a idéia de direito natural fundado na razão. Para o autor, "o direito natural é um ditame da justa razão destinado a mostrar que um ato é moralmente torpe ou moralmente necessário segundo seja ou não conforme à própria natureza racional do homem, e a mostrar que tal ato é, em conseqüência disto vedado ou comandado por Deus, enquanto autor da natureza." Criticando a imutabilidade da natureza humana, diz Bobbio, " Oh naturaleza del hombre, cuántas cosas has podido justificar". BOBBIO, 1965, p. 82. 
únicas causas das infelicidades do mundo, resolveu expor numa declaração solene estes direitos sagrados e inalienáveis, a fim de que todos os cidadãos, podendo comparar sem cessar os atos do Governo com o fim de toda instituição social, não se deixem jamais oprimir e aviltar pela tirania; para que o Povo tenha sempre distante dos olhos as bases da sua liberdade e de sua felicidade, o Magistrado, a regra dos seus deveres, o Legislador, o objeto da sua missão.

Com o surgimento do Estado Liberal pós-revolução francesa, imbuído dos ideais renascentistas da crença do super-homem ${ }^{8}$, ocorre a superação do direito natural, tido, agora, como anti-científico, dada a sua abstração e relatividade. Assim, por meio da escola histórica do direito, movimento contrário à doutrina do direito natural, precursor do positivismo jurídico, abre-se o campo para o florescimento das teorias positivistas de Hans Kelsen (1881-1973).

O positivismo filosófico, cujas idéias reportam-se a Augusto Comte, expressa uma corrente do pensamento que romantiza o postulado científico, em que se busca por meio da metodologia das ciências da natureza (causalexplicativa) alcançar a verdade, a qual já não mais pode ser aceita com base nos pressupostos do inatismo religioso metafísico e sim por meio da precisão científica dos procedimentos lógicos formais .

Kelsen, transportando o positivismo filosófico para o direito, buscou a objetividade científica do ordenamento jurídico. Com isso, retirou todo o conteúdo moral e axiológico do direito, reduzindo a justiça à validade. ${ }^{9}$ Enquanto o direito natural é baseado na dicotomia bom e mau, o direito positivo é indiferente a conceitos valorativos, pois não busca o justo e sim o útil $^{10}$. Para Kelsen, os Juízos de valor (dicotomia bom e mau) são subjetivos e relativos à cada sociedade, ou seja, variam de acordo com o espaço e o tempo, sendo o relativismo axiológico o ponto de partida da teoria positivista

$8 \quad$ NIETZSCHE, 1994.

9 Para Bobbio, “ enquanto para um jusnaturalista clássico teria, ou melhor dizendo, deveria ter, valor de comando só o que é justo, para a doutrina oposta é justo só o que é comandado e pelo fato de ser comandado. Para um jusnaturalista, uma norma não é valida se não é justa; para a teoria oposta, uma norma é justa somente se for válida. BOBBIO, 2001, pp.58-62. 
do direito ${ }^{11}$. Como noções básicas do direito positivo apresentam-se : (i) o direito é particular a determinado contexto histórico, tendo como nota a variabilidade; (ii) só corresponde à noção de direito aquelas normas postas pela autoridade competente; (iii) pretensão de cientificidade do direito, ou seja, a busca de uma neutralidade cientifica no campo jurídico. ${ }^{12}$

Interessante é o apontamento de Karl Larenz sobre a relatividade moral e a abstenção valorativa atribuída ao positivismo.

A humildade cientifica do positivista não exclui que ele tenha para si valores ou exigência éticas; só que os remete para o mundo das crenças pessoais e das convicções morais sobre os quais, do seu ponto de vista não é possível um enunciado científico. Ele não nega, por exemplo, que a exigência da justiça valha para a consciência de cada um, mas é de opinião de que ela não é passível de conhecimento científico e de que, portanto, não constitui um princípio de ciência juspositivista ${ }^{13}$.

Assim, para a teoria do positivismo jurídico, o conceito de justiça deve ser distinguido do conceito de validade, sendo esta prescindível àquela. Para o direito natural as prescrições só poderiam ser consideradas válidas quando fossem justas, isto é, direito válido é direito justo. Já para o positivismo a validade do direito independente de ideais de justiça, sendo o direito válido o direito posto, podendo ocorrer a validade até mesmo do direito injusto. ${ }^{14}$ Em síntese, todo comportamento, justo ou injusto, pode ser conteúdo de uma norma jurídica, pois o que faz uma regra jurídica não é o seu conteúdo, e sim a sua criação (teoria do mandato) ou a sua execução (teoria do direito como ordem coativa). ${ }^{15}$

11 Karl Mannheim aponta o relativismo da idéia de postulados universais, dizendo que cada estrato social possui seus valores, os quais são considerados por eles absolutos. Todavia, os interesses de um grupo social podem ser contrários aos interesses dos outros grupos, o que traz a relativização do absoluto. MANNHEIM, s/d, p. 251-3.

KELSEN, 1998, pp. 19-25.

13 LARENZ, 2005, p. 46.

14 KELSEN, 2003, pp. 66-7.

15 BOBBIO, 1965, p. 73. 
Entretanto, a banalização do mal ${ }^{16}$ ao longo da primeira metade do século XX e a constatação, sobretudo após as duas grandes guerras e as experiências do fascismo, do nazismo e do comunismo, de que a legalidade formal poderia encobrir a barbárie levaram à superação do positivismo estrito e ao desenvolvimento de uma dogmática principialista também identificada como pós-positivismo. O direito natural que dominou os séculos XVII e XVIII, após estes nefastos eventos, volta a ser objeto de debates políticofilosoficos e jurídicos.

Neste enfoque, o pós-positivismo surge com o escopo de reincorporar no direito positivo os preceitos éticos de justiça, constitucionalizando, explícita ou implicitamente, por meio de princípios axiológicos, os valores que anteriormente vagavam em uma esfera notadamente abstrata. Trata-se de analisar o direito não apenas como ordem coativa baseada no dogma da autoridade, e sim a busca de sua legitimação popular ${ }^{17}$. Portanto, podemos inferir que por meio da constitucionalização dos princípios e dos direitos fundamentais, busca-se a positivação do direito natural. ${ }^{18}$

Por conseguinte, no pós-positivismo, por meio dos princípios constitucionais, explícitos ou implícitos, entrelaça-se a ordem jurídica positiva e a ordem moral. Todavia, deve ser gizada que a idéia de subordinação do direito positivo ao direito natural é obsoleta, remontando ao mundo prémoderno. No mundo pós-moderno, a moral e o direito positivo encontram-se em campos autônomos fundamentados em uma relação de complementação recíproca. ${ }^{19}$

\section{Princípios e Regras}

Como reconhece Paulo Bonavides, "a teoria dos princípios é o

$16 \quad$ ARENDT, 1999.

17 Niklas Luhmann afirma que a legitimidade não reside apenas na superioridade da força física, pois se assim fosse, ocorreria um regime de terror extremamente instável. Por isso, são incorporados dispositivos que legitimam a imposição de normas, tais como a eleição política, o processo legislativo e o processo judiciário. LUHMANN, 1983, pp. 65-70.

18 Neste sentido afirma Tércio Sampaio Ferraz que uma das razões do enfraquecimento operacional da dicotomia entre direito natural e positivo se dá através da promulgação constitucional dos direitos fundamentais. "Essa promulgação, o estabelecimento do direito natural na forma de normas postas na Constituição, de algum modo positivou-o.” FERRAZ JUNIOR, 2007, p. 171. 
coração das Constituições na era do pós-positivismo." ${ }^{20}$ Sob essa perspectiva, para melhor compreensão da teoria neoconstitucionalista, especialmente no que respeita à colisão de direitos fundamentais, necessário se faz ingressar na já clássica distinção estrutural entre princípios e regras ${ }^{21}$, cujos teóricos que mais influência exerceram nesta distinção, no direito contemporâneo, foram Robert Alexy e Ronald Dworkin.

Antes porém, com fundamento no pensamento de Paulo Bonavides ${ }^{22}$, miremos, ainda que sinteticamente, a compreensão dos princípios sob a ideologia jusnaturalista, passando pela juspositivista, até chegarmos ao atual momento constitucional. Com efeito, nota-se que no período jusnaturalista os princípios estavam conectados à pretensa idéia de justiça universal. Inseridos em preceitos metafísicos e atemporais, sua normatividade era basicamente nula e duvidosa. No positivismo, dada a influência jusprivatista, originária do direito romano, os princípios começam a ingressar nos códigos como fonte normativa subsidiária, com o fito principalmente de superar as lacunas existentes. Hodiernamente, na fase pós-positivista, com a ascensão do direito público, as novas Constituições iniciam a positivação-constitucionalização dos princípios, os transformando, segundo Bonavides, em pedestal normativo sobre o qual se assenta todo o edifício jurídico dos novos sistemas constitucionais. Portanto, na atual quadra, os princípios são compreendidos como pautas valorativas ordenadoras à criação e aplicação das regras jurídicas que, em virtude de sua própria força de convicção, podem justificar resoluções jurídicas. ${ }^{23}$

No neoconstitucionalismo, os princípios constitucionais, a partir da positivação de conteúdos substanciais, servem de conexão interna entre direito e moral, sendo considerados como janelas por onde a moralidade ingressa no ordenamento jurídico ${ }^{24}$. Nessa linha de pensamento, sustenta Enterría,

20 BONAVIDES, 2004, p. 264.

21 Certo é que vários outros critérios são utilizados para a diferenciação entre princípios e regras. Neste trabalho, todavia, o foco será a diferenciação estrutural, haja vista a sua aplicabilidade no caso de conflitos entre direitos fundamentais. Para uma síntese das distinções existentes entre regras e princípios v. ROTHENBURG, 1999. 
o pensamento jurídico ocidental está sendo conduzido a uma concepção substancialista e não formal do direito, cujo ponto de penetração mais que uma metafísica da justiça, em um axioma de matéria legal, tem sido encontrado nos princípios gerais do direito, expressão desde logo de uma justiça material, porém especificada tecnicamente em função dos problemas jurídicos concretos $^{25}$.

Assim, a partir de sua textura aberta, o direito, incorporando forte carga axiológica ${ }^{26}$, é visto como ele deve ser. Os princípios são entendidos, então, como mecanismos de orientação e condução do direito, emanando os valores que inspiram a criação do ordenamento jurídico, podendo constar expressamente do texto constitucional, como é o caso do princípio da dignidade da pessoa humana, ou implicitamente como acontece com o princípio da proporcionalidade. Seu teor de abstração e a forte carga axiológica permitem que a Constituição acompanhe a dinâmica social sem se tornar anacrônica.

Necessário se faz ressaltar que sob o signo norma ${ }^{27}$, nos dias de hoje, encontram-se incluídos tanto os princípios quanto as regras, sendo - em ambos - as prescrições situadas no plano do dever-ser e seus juízos formulados através dos modais deônticos do proibido, permitido e obrigado ${ }^{28}$. Como afirma Alexy, "os princípios, assim como as regras, são razões para juízos concretos de dever ser, ainda que de um tipo muito diferente. A distinção entre regras e princípios é, pois, uma distinção entre dois tipos de normas." 29

Todavia, a par dessa consideração inicial, o que deve se entender com relação ao signo princípio? Antes da atual concepção normativa, várias

ENTERRÍA, 1986, p.30.

26 A abertura axiológica dos princípios permite a incorporação dos valores jurídicos plurais imanentes na sociedade. $c f$. BARCELLOS, 2002, p. 40.

27 Cabe ressaltar que a doutrina moderna vem a diferenciar os signos enunciado normativo e norma. Enunciado normativo seria o texto, os signos lingüísticos que se fazem presentes no dispositivo constitucional ou legal. Já a norma seria o produto da aplicação do enunciado a uma determinada situação, é dizer, a norma é a concretização do enunciado normativo, o sentido construído pela interpretação do enunciado normativo. MULLER, 1999, p. 124. 
definições haviam sido estabelecidas no sentido de sua compreensão, sendo a idéia central e comum a todas as antigas formulações o estabelecimento de função meramente diretiva e generalista. É de se observar que tal concepção não outorgava o caráter normativo aos princípios, a qual começará a ser proposta, segundo nos informa Paulo Bonavides, ${ }^{30}$ por meio das formulações de Jean Boulanger, que afirmava serem os princípios jurídicos os materiais mediante os quais se pode edificar com confiança a construção jurídica. Posteriormente, a teoria da normatividade dos princípios recebe o contributo, em 1952, de Crisafulli, que afirmava ser o princípio toda norma determinante de uma ou de várias outras normas que lhe são subordinadas (característica normogenética dos princípios) ${ }^{31}$.

Efetivamente, é a partir de Dworkin e Alexy, sob as bases do novo constitucionalismo, que se inicia o tratamento dos princípios como norma, descartando-se a concepção naturalista idealizadora de uma justiça absoluta e imutável e do positivismo com seus princípios gerais de direito de função meramente supletiva. Nesse sentido, apontam-se os princípios não apenas como colmatadores de lacunas do ordenamento jurídico, mas também e, principalmente, como um ponto de superação do positivismo jurídico, especialmente no que se refere à exclusão da discricionariedade judicial e à vinculação entre o direito e a moral ${ }^{32}$.

Para Dworkin a diferença entre regras e princípios é de natureza lógica e decorre do seu mecanismo de aplicação. As regras, segundo o autor, são aplicáveis à maneira disjuntiva do tudo-ou-nada (an all or nothing), ou são aplicáveis ou não, isto é, se ocorrerem os fatos descritos na hipótese de incidência, e se esta regra for considerada válida segundo seu fundamento de validade, as prescrições legais incidirão sobre o fato previsto e, conseqüentemente, serão afastadas outras regras que sejam conflitantes com ela, haja vista que, em se tratando de regras jurídicas, não poderão existir antinomias. Portanto, as regras são biunívocas, valem ou não valem (an all or nothing), não se admitindo gradações. Se duas regras contraditórias, integrantes da mesma ordem jurídica, regularem o mesmo fato social, haverá a necessidade de se afastar uma delas, pois no conflito entre regras, uma

31 Apontando a característica normogenética dos princípios, afirma Johannes Hessen, citando Switalsky, "o que garante a validade dos princípios não é a vivencia matizada da evidência, mas sim a íntima intuição da fecundidade sistêmica dos mesmos. HESSEN, 1979, p. 159. 
delas não pode ser válida.

Como mecanismo de resolução do conflito entre regras, Dworkin, aderindo à concepção tradicional, aponta que o sistema jurídico pode regular tais conflitos através de vários mecanismos, tais como aqueles que conferem primazia à regra promulgada pela autoridade superior (critério hierárquico), à regra promulgada mais recentemente (critério cronológico) e à regra mais específica (critério da especialidade), ou através da escolha da regra que tiver como fundamento os princípios mais importantes ${ }^{33}$.

Os princípios, segundo Dworkin, além da característica de abstração e indeterminação (vaguidade de conteúdo) que lhes é inerente, e o fato de servirem de formulação de diretrizes à aplicação e desenvolvimento do direito, possuem uma dimensão que não é própria das regras jurídicas: seu peso, importância ou valor (são axiológicos). Sua carga valorativa emana o fundamento de eticidade adotado pelo Estado, indicando uma direção a seguir na busca de um imperativo de justiça e equidade. Os princípios tornam-se, então, a ponte que liga a moral ao direito, abrindo-o aos valores que foram afastados pelo rigor lógico-formal do período juspositivista.

Nessa perspectiva, nas modernas sociedades pluralistas, freqüentemente ocorre o intercruzamento de valores, os quais não poderão ser resolvidos segundo o método do tudo-ou-nada, isto é, através da decisão de validade ou invalidade de um dos princípios. Assim, na ocorrência de colisão $0^{34}$ entre princípios, a decisão deverá se basear no peso relativo de cada um deles. O que se pretende afirmar é que na eventualidade de antinomias principiológicas, o julgador deverá realizar uma ponderação, "um jogo concertado de recíproca integração e restrição" ${ }^{\prime 35} \mathrm{em}$ que se pondera e relativiza o peso dos princípios concorrentes ${ }^{36}$. Em suma, na dimensão dos

33 DWORKIN, 2002, pp. 35-46.

34 Inocêncio Mártires Coelho aponta que entre princípios não há que se falar de colisão e sim de momentâneos estados de tensão ou mal-estar hermenêutico que o operador jurídico prima facie verifica serem passageiros e plenamente superáveis no curso do processo de aplicação do direito. COELHO, 2007 , p. 69.

LARENZ, 2005, p. 236.

36 Recentemente, o Supremo Tribunal Federal realizou nítida ponderação de princípios no julgamento da admissão da transferência de dados obtidos mediante interceptação telefônica. O Ministro Relator, César Peluso, afirmou que a restrição constitucional (CF, art. $5^{\circ}$, XII) tem por escopo a preservação da intimidade como bem jurídico privado, essencial à dignidade da pessoa, até o limite em que esse valor, surgindo como óbice à repressão criminal, cede à manifesta superioridade do interesse público na apuração e punição de crime grave enquanto o mais conspícuo dos atentados às condições fundamentais da subsistência da vida social. STF, Inquérito 2424 QO/RJ, rel. Min. Cezar Peluso, 25.4.2007. 
princípios prepondera o processo dialético de "convivência e conciliação." 37 Sendo assim, um princípio que deixar de ser aplicado em um problema concreto poderá ser aplicado em outra situação de tensão sem que com isto possa-se falar em sua invalidade.

Adotando a tese de que a diferença entre princípios e regras não se baseia apenas no teor de generalidade e abstração, também Alexy afirma que a dessemelhança não é somente de grau, mas também qualitativa. Os princípios, tanto para Alexy quanto para Dworkin, não são meras regras com um alto nível de generalidade. Apresentam diferenças conceituais ou qualitativas entre si. Para Alexy, que considera a distinção entre regras e princípios como um dos pilares essenciais da teoria dos direitos fundamentais ${ }^{38}$, o ponto de partida da distinção é que os princípios são normas ordenadoras de que algo se realize na maior medida possível, dentro das possibilidades jurídicas e reais existentes, é dizer, são mandatos de otimização, pois podem ser cumpridos em diferentes graus, e a medida do seu cumprimento não depende apenas das possibilidades reais, mas também das possibilidades jurídicas, cujo âmbito de possibilidade é delimitado pela intersecção de princípios e regras opostos.

Estabelecidas estas diretrizes e considerados os princípios como mandatos de otimização, pode-se inferir que não são eles comandos definitivos. Daí decorrerem apenas disposições prima facie, pois o fato de um princípio valer para a solução de um caso não significa que ele valha como resultado definitivo em todos os outros casos. Para Alexy, as regras - por ele chamadas de comandos definitivos - de forma diversa, contêm determinações no âmbito do fático e juridicamente possível, determinando o cumprimento de suas disposições em sua exata medida, é dizer, estando limitadas pela análise da validade, só podem ser cumpridas ou não. Se válida a regra, deverá fazer-se o que por ela prescrito definitivamente, se inválida não poderá ser exigido o seu cumprimento. Portanto, as regras, se válidas, constituem razões definitivas que excluem qualquer outra melhor solução. Se a hipótese de incidência for preenchida, a conseqüência normativa deve ser aceita. Já os princípios são razões prima facie para a resolução do conflito em um dado sentido, pois constituem fundamentos que devem ser ponderados com os fundamentos de outros princípios. Assim, a forma característica da aplicação das regras é a subsunção e a dos princípios a ponderação. Por conseguinte, afirma Alexy, a diferença entre regras e princípios é qualitativa 
e não de grau. ${ }^{39}$

Finalmente e por todos, em consolidação às diferenças entre princípios e regras apresentadas, reconhecendo a importância da distinção estruturalista ou morfológica, mas não se atendo meramente a esta perspectiva, Canotilho apresenta uma proposta sistematizadora das principais características distintivas:

i) Grau de abstração: os princípios são normas com um grau de abstração relativamente elevado; de modo diverso, as regras possuem uma abstração relativamente reduzida.

ii) Grau de determinabilidade na aplicação do caso concreto: os princípios, por serem vagos e indeterminados, carecem de mediações concretizadoras, enquanto as regras são suscetíveis de aplicação direta.

iii) Caráter de fundamentalidade no sistema das fontes de direito: os princípios são normas de natureza ou com um papel fundamental no ordenamento jurídico devido à sua posição hierárquica no sistema das fontes (ex: princípios constitucionais) ou à sua importância estruturante dentro do sistema jurídico (ex: princípio do Estado de Direito).

iv) Proximidade da idéia de direito: os princípios são standards juridicamente vinculantes radicados nas exigências de justiça (Dworkin) ou na idéia de direito (Larenz); as regras podem ser normas vinculativas com um conteúdo meramente funcional.

v) Natureza normogenética: os princípios são fundamento de regras, isto é, são normas que estão na base ou constituem a ratio de regras jurídicas, desempenhando, por isso, uma função normogenética fundamentante. ${ }^{40}$

39 ALEXY, 1993, pp. 86-101. 


\section{Da colisão de princípios}

O fenômeno da colisão de valores nas sociedades contemporâneas, particularmente complexas e plurais, é cada vez mais recorrente. Se os valores que permeiam a sociedade são distintos, certamente os conflitos serão habituais e, como afirma Larenz, "em caso de conflito, se se quiser que a paz jurídica se restabeleça, um ou outro direito (ou um dos bens jurídicos em causa) tem que ceder até um certo ponto perante o outro ou cada um entre si". 41

Quando da existência de conflitos, contradições ou antinomias normativas, o sistema jurídico normalmente estabelece métodos de resolução para que seja obtida a salvaguarda da unidade e da coerência do ordenamento jurídico. No conflito entre regras, quando sua aplicação independente leve a soluções contraditórias, duas soluções poderão ser adotadas: (i) cria-se uma norma de exceção que compatibilize a aplicação das duas regras, com isso removendo a situação de oposição, ou (ii) declara-se inválida uma das regras conflitantes e com isso a elimina do ordenamento jurídico ${ }^{42}$.

Na seara dos princípios, a solução em face das antinomias normativas é realizada de maneira distinta. A colisão de princípios é fenômeno típico do novo constitucionalismo que, fundamentado na constitucionalização dos princípios jurídicos e na consolidação de sua eficácia imediata e vinculante, trouxe maior complexidade ao sistema jurídico hodierno, sobretudo naquelas constituições analíticas - como é o caso da brasileira - em que se aposta na abertura semântica de seus enunciados normativos. Como reconhece José Carlos Vieira de Andrade, as situações de conflito tornam-se habituais em decorrência do alargamento do âmbito de proteção dos direitos fundamentais, fazendo com que as liberdades fundamentais adquiram novas facetas, daí surgindo situações de oposição. Como afirma o autor lusitano,

Poderá ser, por exemplo, o caso da liberdade de expressão ou de imprensa, quando se oponha à intimidade da vida privada, ao direito ao bom nome e à reputação, à segurança nacional, ao respeito pelas instituições ou à moral pública. Uma revista ou um filme considerados

$41 \quad$ LARENZ, 2005, p. 575. 
pornográficos deverão ser proibidos?Poderão os jornais discutir problemas de segurança do Estado? Não poderão os governantes ser criticados na sua pessoa ou nos seus actos? Poderá advogar-se o derrube do governo constituído de forma pública? Poderá um jornalista entrevistar um preso? Ou um jornal comentar um caso em julgamento? $\mathrm{Ou}$, noutros campos, deverá punir-se por homicídio um pai que, por convicção religiosa não permite que se faça uma transfusão de sangue a um seu filho menor, necessária para o manter vivo? Poderá ser absoluta a proibição do aborto?Poderá um cidadão recusar-se a prestar serviço militar em caso de guerra, por razões de consciência? Até que ponto podem os pais dispor da maneira de viver dos filhos? ${ }^{43}$

Assim, nestas Constituições prolixas, onde o pluralismo axiológico gera conflitos normativos, os métodos clássicos de resolução de antinomias jurídicas, fundamentados na aferição da validade ou invalidade das normas conflitantes - usuais quando se verifica a contradição entre regras jurídicas - não conseguem responder satisfatoriamente às colisões entre princípios jurídicos, os quais, vencida a aferição de validade, são analisados sob o prisma do peso, valor e importância.

Por outras palavras, isto significa que, no caso concreto, a adoção de um princípio não traz como conseqüência a invalidade de seu antípoda. Como salienta Canotilho, a convivência dos princípios é conflitual (Zagreblesky) e a convivência de regras é antinômica. Os princípios coexistem e as regras antinômicas excluem-se. ${ }^{44} \mathrm{Na}$ verdade, se em dado caso, debaixo de certas circunstâncias, optou-se por um deles, nada impede que em outra situação, em circunstâncias distintas, se aplique o princípio contrário. Assim, no problema jurídico concreto, deverá se verificar qual dos princípios possui maior peso, numa relação de precedência condicionada, analisando qual terá prevalência sobre o que possui menor peso.

$\mathrm{Na}$ linguagem de Alexy dir-se-ia que,

quando dois princípios entram em colisão - tal como ocorre quando segundo um princípio algo é proibido 
e, segundo outro princípio, é permitido - um dos dois princípios têm que ceder ante o outro. Entretanto, isto não significa declarar inválido o princípio desprezado nem que no princípio desprezado deva-se introduzir uma cláusula de exceção. De fato, o que sucede é que, sob certas circunstâncias um dos princípios precede ao outro. Sob outras circunstâncias, a questão da precedência pode ser solucionada de maneira inversa. Isto é o que se quer dizer quando se afirma que nos casos concretos os princípios possuem diferente peso e que tem primazia o princípio com maior peso. Os conflitos de regras se resolvem na dimensão de validade; a colisão de princípios - como somente podem entrar em colisão princípios válidos - têm lugar a partir da superação da dimensão da validade, na dimensão de peso ${ }^{45}$.

Registre-se apenas que a aferição de peso não se dá abstratamente, somente ocorrendo no caso concreto, em lídimo caráter relacional, por meio da denominada técnica da ponderação de valores. Novamente em palavras de Alexy,

Princípios e ponderações são dois lados do mesmo objeto. Um é do tipo teórico-normativo, o outro, metodológico. Quem efetua ponderações no direito pressupõe que as normas, entre as quais é ponderado, têm a estrutura de princípios e quem classifica normas como princípios deve chegar a ponderações. A discussão sobre a teoria dos princípios é, com isso, essencialmente, uma discussão sobre a ponderação. ${ }^{46}$

A técnica da ponderação de valores ou de interesses - método utilizado quando a subsunção é insuficiente - procura aferir o peso de cada um dos princípios opostos entre si e, a partir do caso concreto, fazer concessões recíprocas, sacrificando de forma mínima os princípios diretamente contraditórios ${ }^{47}$. Nessa perspectiva, ocorrendo uma contradição

ALEXY, 1993, p. 89.

ALEXY, 1999, p. 75. 
entre princípios, cada qual deverá ceder perante o outro, de modo que ambos tenham atuação em termos ótimos (mandado de otimização). Isso é assim porque não existe superioridade de um dos princípios utilizados, mas sim a utilização daquele que se aferir mais adequado na realidade do caso analisado, em função da qual um dos princípios, debaixo das condições apresentadas, recebe prevalência. ${ }^{48}$ Utilizando a linguagem do próprio Alexy, entre os princípios não existe "prioridade sem mais", devendo o conflito ser solucionado por meio de uma ponderação entre os interesses contrapostos, de forma a obter o melhor equilíbrio entre as normas em estado de tensão. ${ }^{49}$

A ponderação decorre da necessidade de os participantes de uma sociedade cada vez mais complexa e plural aceitarem reciprocamente as perspectivas e valores do outro, de forma a equilibrar racionalmente seus interesses, realizando renúncias recíprocas para a obtenção de uma obra conciliatória. Konrad Hesse, ao analisar o princípio da unidade da Constituição, aponta que

onde nascem colizões (sic) não deve, em ponderação de bens precipitada ou até ponderação de valor abstrata, um ser realizado à custa do outro. Antes, o princípio da unidade da Constituição põe a tarefa de uma otimização: a ambos os bens devem ser traçados limites, para que ambos possam chegar a eficácia ótima. ${ }^{50}$

Isto reflete a necessidade de se alcançar a concordância prática nas situações de conflito normativo, em que "bens jurídicos protegidos jurídicoconstitucionalmente devem, na resolução do problema, ser coordenados um ao outro de tal modo que cada um deles ganhe realidade." ${ }^{51}$

A propósito do princípio da concordância prática, afirma José Carlos Vieira de Andrade:

A solução dos conflitos ou colisão não pode ser resolvida com o recurso à ideia de uma ordem hierárquica dos valores constitucionais. Não se pode sempre (ou talvez nunca) estabelecer uma hierarquia entre os bens para

$48 \quad$ Id. Ibidem, pp. 574-88; 674-86.

49 ALEXY, 1993, p. 90.

$50 \quad$ HESSE, 1999. p. 66

$51 \quad$ Id. Ibidem. 
sacrificar os menos importantes. Os próprios bens da vida e integridade pessoal, que o n. $^{\circ} 4$ do artigo $19 .^{\circ}$ parece positivamente considerar como bens supremos, podem ser sacrificados, total ou parcialmente ${ }^{52}$.

Assentados estes pressupostos, a relação de tensão entre princípios não pode ser solucionada no sentido de uma prioridade absoluta de um dos princípios abstratamente considerado, devendo encontrar-se a saída por meio da ponderação dos interesses opostos, aferindo-se qual deles possui maior peso diante das circunstâncias do caso concreto. Alexy denomina esta técnica de "relação de precedência condicionada" pois, na resolução do caso concreto, se indicam as condições perante as quais um princípio precede ao outro, ressalvando que debaixo de outras condições a questão da precedência poderá ser solucionada de forma diversa. ${ }^{53}$ É este o sentido da denominada "Lei de Colisão", a qual estabelece a inexistência de relações absolutas de precedência. Não existindo um princípio que sempre prepondere sobre os demais, sempre devem ser levadas em consideração as situações específicas do caso.

Em importante passagem, Inocêncio Mártires Coelho, discorrendo sobre a ponderação de valores, disserta que

a priori não existe uma hierarquia fixa e abstrata entre os diversos princípios, ressalvada - porque fora de cotejo axiológico - apenas a dignidade da pessoa humana como valor-fonte dos demais valores, como valor fundante da experiência ética ou, se preferirmos, como princípio e fim de toda ordem jurídica ${ }^{54}$.

Saliente-se que Alexy e Dworkin não compartilham da idéia

ANDRADE, 1998, p. 221

53 Juarez de Freitas cita um interessante exemplo de ponderação entre princípios: "Caso emblemático no Direito Comparado é o do prisioneiro que faz greve de fome. Após acesa polêmica, a solução encontrada foi a de fazer valer o direito à vida sobre a liberdade de expressão, contudo o soro somente foi aplicado quando o grevista caiu inconsciente, uma vez que, neste estado, não haveria sentido falar propriamente em liberdade de expressão". FREITAS, 1999, p. 406.

54 COELHO, 2002, p 49. Bobbio também aponta a existência, ainda que excepcional, de direitos absolutos. Para este autor, o direito de não ser escravizado e o direito a não ser torturado são direitos privilegiados, pois "não são postos em concorrência com outros direitos, ainda que também fundamentais." BOBBIO, 2004, p. 40. 
da existência de princípios absolutos, é dizer, aqueles princípios que em nenhum caso podem ser deslocados por outros princípios. Segundo Alexy, inclusive a dignidade da pessoa humana, considerada como núcleo essencial do constitucionalismo moderno, embora possua um grande número de casos de precedência sobre os outros princípios, poderá ser submetida à técnica da ponderação, como aconteceu em julgamento realizado pelo Tribunal Constitucional Alemão onde se discutia a proibição de indulto no caso de apenados à prisão perpétua. Nesse caso, o Tribunal Constitucional apontou que, em razão da periculosidade permanente do detento, a proteção da comunidade precederia à dignidade da pessoa humana ${ }^{55}$. Assim, como afirmou Alexy, "com esta formulação, constata-se que a proteção da comunidade estatal, sob as condições indicadas, precede o princípio da dignidade da pessoa humana. Dadas outras condições, a preferência pode ser fixada de outra maneira." ${ }^{.56}$

Para Bobbio a caracterização de direitos absolutos é muitas vezes uma posição conservadora que tenta impedir o surgimento de novos direitos.

Basta pensar nos empecilhos colocados ao progresso da legislação social pela teoria jusnaturalista do fundamento absoluto da propriedade (...). O fundamento absoluto não é apenas uma ilusão; em alguns casos, é também um pretexto para defender posições conservadoras. ${ }^{57}$

Apesar disso, uma das grandes preocupações da ponderação de princípios como critério de resolução de conflitos principiológicos é a incerteza dela decorrente. Como observado por Jorge Reis Novais,

Impossibilidade de colher da Constituição parâmetros materiais susceptíveis de balizar objectivamente o recurso ao método, subjectivismo, intuicionismo e arbitrariedade, transferência ilegítima

55 ALEXY, 1993, pp. 105-9. Para Karl Larenz a vida humana e a dignidade humana são fixadas como valores de escalão superior frente a outros bens. LARENZ, 2005, p. 586.

56 ALEXY, 1993, p. 108. Para Ingo Wolfgang Sarlet a dignidade da pessoa humana somente entra em rota de colisão com a dignidade da pessoa humana de pessoa diversa, é dizer, se a dignidade da pessoa humana é considerado valor sobreposto a todos os outros valores constitucionais, somente seria possível o seu conflito consigo mesma. SARLET, 2006, pp. 124-41. 
de poderes do legislativo para o juiz com substituição da reserva de lei pela reserva de sentença, dissolução dos controles típicos de Estado de Direito, corrosão da força normativa da Constituição, nivelação e indiferenciação dos direitos fundamentais, tirania dos valores e fórmula vazia, de tudo a ponderação de bens no domínio dos direitos fundamentais tem sido, e com argumentos de peso, acusada ${ }^{58}$.

No mesmo sentido, salienta Eros Grau,

não há, no sistema, nenhuma norma a orientar o intérprete e o aplicador a propósito de qual dos princípios, no conflito entre eles estabelecido, deve ser privilegiado, qual o que deve ser desprezado. Em cada caso, pois, em cada situação, a dimensão do peso ou importância dos princípios deve ser ponderada. ${ }^{59}$.

Disso decorre que, sob pena de inadmissível arbitrariedade, as decisões tomadas pelos detentores do poder devem ser realizadas não com argumentos privados, íntimos, subjetivos, mas através de argumentos públicos aptos a legitimar suas decisões perante a comunidade.É fruto dessas reflexões que Alexy aponta a fundamentação das decisões como medida de controle da racionalidade da decisão. Para o autor "uma ponderação é racional se o enunciado de preferência a que conduz pode ser fundamentado racionalmente." ${ }^{60}$

Com efeito, aduz Alexy que a solução do conflito principiológico é guiada pela máxima da proporcionalidade, aliada a um racional procedimento de argumentação jurídica. O princípio da proporcionalidade (denominação adotada pelos alemães) ou da razoabilidade (denominação adotada pelos norte-americanos) é decomposto em três subprincípios: a adequação,

$58 \quad$ NOVAIS, 2003, p.640.

59 GRAU, 1993, p. 142.

60 Alexy, a partir da lei de ponderação estabelece como critério de fundamentação da ponderação entre os princípios que quanto mais intensiva é uma intervenção em um direito fundamental tanto mais graves devem ser as razões que a justifiquem, elabora as três fases da ponderação: (i) na primeira fase, deve ser determinada a intensidade da intervenção; (ii) na segunda fase, trata-se, então, da importância das razões que justificam a intervenção; e (iii) somente na terceira fase, sucede, então, a ponderação em sentido estrito e próprio. ALEXY, 1993, pp. 158-159. 
a necessidade e a proporcionalidade em sentido estrito ${ }^{61} \mathrm{~A}$ ponderação realizada nestas três fases reduz as incertezas e permite a opção racional, fundamentada, por um dos princípios escolhidos.

Pela adequação a atividade do poder público deve ser apropriada para a consecução dos objetivos pretendidos pela Constituição Federal. Devese avaliar, em um típico raciocínio de meios e fins, se o meio proposto é levado a realizar as finalidades normativas pretendidas. A necessidade determina que o Estado deve sempre escolher o meio igualmente eficaz e menos oneroso para o cidadão, é dizer, considerada adequada a medida imposta pelo Poder Público, há de se buscar a sua concretização através do meio menos gravoso aos direitos fundamentais afetados. Já a proporcionalidade em sentido estrito - que conforme Alexy seria o postulado da ponderação propriamente dito - exige que o Estado procure sopesar, colocar na balança, as vantagens e desvantagens da medida tomada, e, assim, decidir pela tomada ou não do ato, em um jogo concertado de recíprocas restrições, em que se visa o maior equilíbrio dos direitos em tensão.

Portanto, em conclusão, o princípio da proporcionalidade configurase em importante critério que parametriza a aplicação do julgador nos denominados casos difíceis, em que a técnica da subsunção não se mostrou apta a solucionar os conflitos existentes no ordenamento jurídico. Nos casos difíceis, em que a situação concreta acaba por colocar em tensão princípiosvalores, os quais sinalizam opções axiológicas muitas vezes não só distintas, mas contraditórias, o sopesamento através de um processo essencialmente dialético e racionalmente argumentativo na fundamentação das decisões mostra-se a melhor opção. 


\section{Referências Bibliográficas:}

ABBAGnANO, Nicola. Dicionário de filosofia. São Paulo: Martins Fontes, 2003.

AFTALION, Enrique R, Critica del saber de los juristas. La Plata, 1951.

ALEXY, Robert. Teoria de los derechos fundamentales Madri: Centro de Estúdios Constitucionales, 1993.

. Teoria da argumentação jurídica. São Paulo: Landy, 2001.

ARENDT, HANNAH. Eichmann em jerusalém. São Paulo: Cia das Letras, 1999.

BARROSO, Luís Roberto. Fundamentos teóricos e filosóficos do novo direito constitucional brasileiro (pós-modernidade, teoria critica e pós-positivismo). In: BARROSO, Luis Roberto (organizador). A nova interpretação constitucional. Ponderação, direitos fundamentais e relações privadas. Rio de Janeiro: Renovar, 2003.

BARROSO, Luis Roberto e BARCELLOS, Ana Paula de. A nova Interpretação Constitucional: Ponderação, Argumentação e Papel dos Princípios. In: LEITE: George Salomão. Dos Princípios Constitucionais. São Paulo: Malheiros Editores, 2003.

BOBBIO, Norberto. El problema Del positivismo jurídico. Buenos Aires: EUDEBA, 1965.

.Teoria da norma jurídica. Tradução Fernando Pavan Baptista e Ariani Bueno Sudatti. Bauru, SP:EDIPRO, 2001 Ícone, 1995.

.O positivismo jurídico: Lições de filosofia do direito. São Paulo: .Teoria do ordenamento jurídico. Tradução Maria Celeste C.J. Santos. Brasília: Editora Universidade de Brasília, 10. ed. 1999. 
BONAVIDES. Paulo. Curso de direito constitucional. 14. ed. São Paulo:Malheiros Editores, 2004.

CAMARGO, Marcelo Novelino. “O conteúdo jurídico da dignidade da pessoa humana. In: CAMARGO, Marcelo Novelino (org.) Direito Constitucional: Leituras Complementares. Salvador: JusPODIVM, 2006

CANOTILHO, José Joaquim Gomes.Direito Constitucional. 6.ed.rev Coimbra:Livraria Almedina, 1993.

CHAUİ, Marilena. Convite à filosofia. 13. ed. São Paulo: editora Ática, 2005.

COELHO, Inocêncio Mártires. Elementos de teoria da Constituição e de Interpretação Constitucional. In: MENDES, Gilmar Ferreira. Hermenêutica constitucional e direitos fundamentais. 1.ed. Gilmar Ferreira Mendes, Inocêncio Mártires Coelho, Paulo Gustavo Gonet Branco. Brasília: Brasília Jurídica, 2002.

COMPARATO, Fabio Konder. A afirmação histórica dos direitos humanos. 4. ed. ver. e atual. São Paulo: Saraiva, 2005.

CRISAFULLI, V. La Costituzione e lê sue Disposizioni di Prinicipio, Milão, 1952.

DÍAS, Elias. Curso de Filosofia del Derecho.Madrid: Marcial Pons,1998.

DWORKIN, Ronald. Levando o direito a sério. São Paulo: Martins Fontes, 2002.

.Domínio da Vida: Aborto, eutanásia e liberdades fundamentais. Trad. Jefferson Luiz Camargo. São Paulo: Martins Fontes, 2003.

FERRAZ, Tércio Sampaio. Introdução ao estudo do direito: técnica, decisão, dominação. 4. ed. São Paulo: Atlas, 2003.

HABERMAS, Jürgen. Direito e democracia: entre facticidade e validade, volume I . tradução: Flávio Beno Siebeneichler. Rio de Janeiro: Tempo Brasileiro, 1997. 
HART, Herbert L. A. O conceito de direito. Lisboa: Fundação Calouste Gulbekian, 1994.

HÄBERLE, Peter. A sociedade aberta dos intérpretes da constituição: contribuição para a interpretação pluralista e "procedimental" da constituição. Trad. Gilmar Ferreira Mendes. Porto Alegre: Sergio A. Fabris, 1997.

HEGEL, G. W. F. Princípios de la Filosofía del Derecho. Trad. de Juan Luis Vermal. Buenos Aires: Editorial Sudamericana, 1975.

HESSEN, Johannes. Teoria do conhecimento.Coimbra: Armênio Amado; São Paulo: Martins Fontes, 7.ed, 1979.

KANT, Immanuel. Fundamentação da Metafísica dos Costumes. Trad. Leopoldo Holzbach. São Paulo: Martin Claret, 2005.

KELSEN, Hans. O problema da justiça. Tradução João Baptista Machado. São Paulo: Martins Fontes, 2003.

.Teoria pura do direito. Tradução João Baptista Machado. 6.ed. São Paulo: Martins Fontes, 1998.

.Teoria Geral do Direito e do Estado. Tradução de Luis Carlos Borges. São Paulo: Martins Fontes, 1998.

LARENZ, Karl. Metodologia da ciência do direito.trad. José Lamego. 4.ed. Lisboa: Fundação Calouste Gulbenkian, 2005.

LYRA FILHO, Roberto. A ciência do direito. Revista Noticia do Direito Brasileiro. Brasília: Faculdade de direito da UNB, n. 11, 2005.

LUHMANN, Niklas: Sociologia do direito, Vol.II. Rio de Janeiro: Tempo Brasileiro, 1983.

MANNHEIM, Karl. Sociologia do conhecimento. Lisboa: Rés, vol 1, s/d.

MENDES, Gilmar Ferreira. Hermenêutica constitucional e direitos 
fundamentais.1.ed. 2. tir. Gilmar Ferreira Mendes, Inocêncio Mártires Coelho, Paulo Gustavo Gonet Branco. Brasília: Brasília Jurídica, 2002.

NIETZSCHE, Friedrich Wilhelm. Assim Falava Zaratustra. São Paulo: Behar Editora (hemus), 1994.

POPPER, Karl. O mito do contexto. Lisboa: Edições 70. 1999.

RECASÉNS SICHES, Luis. Tratado General de Filosofia del Derecho. México: Porrúa, 1965.

SARLET, Ingo Wolfgang Sarlet. Dignidade da Pessoa Humana e Direitos fundamentais na Constituição de 1988. 4. ed.rev. atual. Porto Alegre: Livraria do Advogado, 2006.

SILVA, José Afonso. Curso de Direito Constitucional Positivo, $13^{\mathrm{a}}$ ed., São Paulo: Malheiros.

STAMMLER, Rudolf. Tratado de Filosofia del Derecho. Madrid: Réus, 1930.

ZAGREBELSKY, Gustavo. El Derecho Dúctil. Madri: Trotta. 1999. 